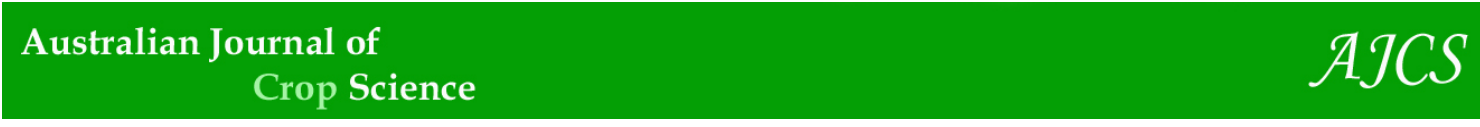

AJCS 10(7):926-932 (2016)

ISSN:1835-2707

DOI: 10.21475/ajcs.2016.10.07.p7301

\title{
Temperature-based solar radiation models for use in simulated soybean potential yield
}

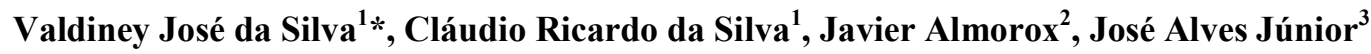 \\ ${ }^{1}$ Institute of Agricultural Sciences, ICIAG, Federal University of Uberlandia - UFU, MG, Brazil \\ ${ }^{2}$ School of Agricultural Engineers, Department of Soil Science and Climatology, Polytechnic University of \\ Madrid, Madrid, Spain \\ ${ }^{3}$ School of Agronomy, EA, Federal University of Goias - UFG, GO, Brazil
}

\section{"Corresponding author: neyjosilva@hotmail.com}

\begin{abstract}
Solar radiation is the main meteorological element required for crop yield simulation. However, it is not widely measured as air temperature and rainfall. This study evaluated some temperature-based solar radiation models for estimation of daily solar radiation $(R s)$, and how the estimates may affect soybean yield potential. The evaluated models were Annandale (AN), Hargreaves (HA), Modified Hargreaves (HA-1), Hunt (HU), Bristow and Campbell (BC), Chen (CH), Donatelli and Campbell (DC) and De Jong and Stewart (JS). This research was carried out using historical data from six sites in the Triangulo Mineiro region, where measured values of $R s$, minimum and maximum air temperature and rainfall were available. The dataset (2009-2014) was separated into two sub-data sets, one for calibration (2009) and the other for evaluation of performance (2010-2014). The Rs estimated data were used in SoySim software to estimate potential soybean yield. Statistical indexes: (a) root mean square error (RMSE), (b) relative root mean square error (RRMSE), (c) coefficient of determination $\left(R^{2}\right)$ and (d) mean error $(M E)$ were used as indicators of the agreement between observed and estimated $R s$ data. After evaluating the performance, $R s$ estimated values for each model were used to simulate the soybean potential yield. Although the eight models have presented similar performance for estimating $R s$ values, when these data were used for simulation of the potential soybean yield, the performances diverged considerably. In this way, only the BC, $\mathrm{CH}, \mathrm{DC}$ and JS models showed satisfactory performance in yield simulation with $R^{2}$ and $R R M S E$ varying from 0.76 to 0.80 and 3 to $4 \%$, respectively. Therefore, the findings suggest that, before choosing the model to estimate $R s$, it is important to define the purpose of use of solar radiation data.
\end{abstract}

Keywords: air temperature, empirical equations, Bristow and Campbell, performance.

Abbreviations: $\Delta T$ _ Daily air temperature range, $\Delta T a_{-}$Annual air temperature range, $A N \_$Annandale estimation model, $B C$ Bristow and Campbell estimation model, $\mathrm{CH}_{-}$Chen estimation model, $\mathrm{DC}$ - Donatelli and Campbell estimation model, $H A \_$Hargreaves estimation model, $H A-I_{-}$Modified Hargreaves estimation model, $H U_{-}$Hunt estimation model, $J S_{-}$De Jong and Stewart estimation model, and $R s_{-}$daily solar radiation incident.

\section{Introduction}

Daily solar radiation incident $(R s)$ data are used in crop yield simulation (Bellocchi et al., 2003; Abraha and Savage, 2008; Mavromatis, 2008; Borges et al., 2010; Wang et al., 2015) and evapotranspiration requirements (Bandyopadhyay et al., 2008; Conceição, 2010; Carvalho et al., 2011; El Nesr et al., 2011). However, because of instrument cost and calibration requirements (Hossain et al. 2014), $R s$ is not widely measured like commonly used air temperature and rainfall data (Weiss and Hays, 2004). Even at stations where $R s$ is measured, there are many days when data lie outside the expected range due to equipment failure and other problems (Hunt et al., 1998). Therefore, in many model simulations, the lack of $R s$ data has often been a significant challenge (Trnka et al., 2007).

The demand for suitable radiation data has in turn, led to the development of numerous predictive methods. However, those are based on empirical relationships using commonly measured meteorological elements such as air temperature data are attractive due to lower data requirement and computation costs (Liu et al., 2009a, 2009b). In addition, the temperature-based solar radiation model can reduce the uncertainty of the crop simulations (Hunt et al., 1998; Rivington et al., 2006; Abraha and Savage 2008).

Although empirically derived and conceptually simple, air temperature-based empirical models are founded on theoretical concepts for energy exchange on the surface boundary layer (Goodin et al., 1999). These models are based on the assumptions that (a) clear skies will increase the daily maximum temperature because of the greater short wave radiation input, while resulting in decreased minimum air temperature due to reduced long wave emission from the atmosphere; and (b) cloudy conditions will decrease the daily maximum air temperature due to reduced air transmissivity, while resulting in increased minimum air temperature due to increased long wave radiation from the clouds (Allen, 1997; Donatelli and Campbell, 1998; Almorox et al., 2013).

Numerous calibrations and evaluations have been made for different climatic regions, such as Canada (De Jong and Stewart, 1993), China (Liu et al., 2009b) Spain (Almorox, 2011) and Brazil (Borges et al., 2010; Silva et al., 2012; Dos Santos et al., 2014). Depending on the model and calibration 
the errors can vary between 0.1 (De Jong and Stewart, 1993) and $17.8 \mathrm{MJm}^{-2} \mathrm{~d}^{-1}$ (Phakamas et al., 2013).

Beyond the evaluation of these models for a wide range of geographical and climate conditions, it is interesting to access how $R s$ estimated values impact other crop process, as evapotranspiration and crop yield. Trnka et al. (2007) found significant variations in yield simulations according to the errors of the models and concluded that these can compromise the accuracy, especially if not properly calibrated. Thereby, the aims of this study were to (i) calibrate various temperature-based solar radiation models in the Triangulo Mineiro region, Brazil and (ii) investigate the impact of estimated $R s$ values on soybean yield potential.

\section{Results}

\section{Calibrated coefficients}

Table 3 shows the results of calibration models. In general, the coefficient values ranged between geographic locations as similar to other reports (Meza and Varas, 2000; Chen et al., 2004; Silva et al., 2012). It should be mentioned that this variation was higher for models with a greater number of coefficients. Thus, for the HA model, which has only one coefficient $(a)$, the values ranged from 0.150 to 0.188 while for the $\mathrm{BC}$ model with its three coefficients $(a, b$ and $c)$, the values were 0.677 to $0.873,0.012$ to 0.039 and 1.304 to 1.997, respectively. Making a percentage comparison, the HA model coefficient showed an average variation of $20 \%$, while for the BC model coefficients of variation was $42 \%$ on average. These results showed that calibration can improve the accuracy of estimates (Liu et al., 2009b; Silva et al., 2012; Phakamas et al., 2013), especially for models with a greater number of coefficients.

\section{Performance of Rs estimation models}

Upon analysis of the $R s$ estimated by the models after calibration (Table 4), it was found that the RMSE and $M E$ values were similar among models. In Sacramento, where the greatest difference between the models occurred, the range of $R M S E$ was 3.08 to $3.68 \mathrm{MJ} \mathrm{m}^{-2}$. This difference based on the daily $R s$ average $\left(18.64 \mathrm{MJ} \mathrm{m}^{-2}\right)$ was close to $3 \%$. In a similar way, in the location with greatest $M E$ variation (Conceicao das Alagoas) this difference was close to $5 \%(-0.02-0.85$ $\mathrm{MJ} \mathrm{m}{ }^{-2}$ ).

Nevertheless, it was possible to identify two groups of performances between models. The $\mathrm{BC}, \mathrm{CH}, \mathrm{DC}$ and JS models were superior to the AN, HA, HA-1 and HU models. Analyzing the values of RMSE, RRMSE and $R^{2}$ for the $\mathrm{CH}$ model, we noted variation from 2.84 to $3.78,14.87$ to 19.21 and 0.59 to 0.70 , respectively. Similarly, the BC and DC models showed range for RMSE, RRMSE and $R^{2}$ next to $\mathrm{CH}$. On the other hand, the AN, HA and HA-1 models showed values of $R M S E$ and $R^{2}$ ranging of 3.05 to $3.94,15.57$ to 20.04 and 0.48 to 0.64 , respectively. In general, the values obtained for RMSE were closely similar to Almorox (2011), but the $R^{2}$ were minor. For the models that use rainfall data (JS and HU), the performance were not different from the others models that use only $\Delta T$ data. Thus, the performance of JS model was similar to $\mathrm{BC}, \mathrm{CH}$ and DC models, and the HU was similar to AN, HA and HA-1 models. Then, the inclusion of rainfall data did not improve the estimation of Rs. However, in contrast, Almorox (2011) found best estimates when used the HU model comparing with models that use only air temperature data in China.
An important observation is that all models showed better performances (Table 4) in sites with higher annual mean air temperature range $(\Delta T a)$ (Table 1$)$. While Conceicao das Alagoas, with higher $\Delta T a(13.48)$, showed best performance, Uberlandia, with lower $\Delta T a(10.30)$, was the worst. These results agreed with those obtained by Liu et al. (2009b) in China. However, despite of similar comportment between the models, some were more dependent to $\Delta T$. The linear regressions between the $\triangle T a$ and values of RMSE confirm this dependency (Fig 1). For the AN, HA and HA-1 models the values of $R^{2}$ ranged from 0.54 to 0.57 . In the $\mathrm{BC}, \mathrm{CH}$ and $\mathrm{DC}$, models ranged from 0.26 to 0.43 and in the JS and HU models, which also used rainfall data, the range was 0.04 and 0.23 , respectively.

\section{Application of the estimated Rs values on soybean potential yield simulation}

When the Rs values estimated by the models were used in the simulation of the soybean potential yield, the $\mathrm{BC}, \mathrm{CH}, \mathrm{DC}$ and JS models showed $R^{2}>0.75$ for the locations and years under evaluation (Fig 2). On the other hand, the AN, HA, HA- 1 and HU models showed $R^{2} \leq 0.35$. It can also be verified that all the models showed a general tendency to overestimate the potential soybean yield, as shown by the positive values of $M E$. However, for the AN, HA, HA-1 and HU models, this tendency was higher than the other models with values ranging between $0.22-0.25 \mathrm{Mg} \mathrm{ha}^{-1}$, while the $\mathrm{BC}, \mathrm{CH}, \mathrm{DC}$ and JS models presented values from 0.04 $0.11 \mathrm{Mg} \mathrm{ha}^{-1}$. A lower $R^{2}$ combining with a higher $M E$ indicates poor performance, since in a certain location or year, errors in the simulations can be higher. Thus, while the errors for the BC, CH, DC and JS models do not exceeded $10 \%$, in the AN, HA, HA-1 and HU models came close to $35 \%$ in Ituiutaba for the 2009/2010 crop season.

Abraha and Savage (2008) verified an overestimation of total dry corn biomass with the HA-1 model. However, these authors recommend the referred model due to its simplicity and the relative easiness in obtaining the coefficients for a given location. Moreover, Bandyopadhyay et al. (2008) and El Nesr et al. (2011) found minor effect of $R s$ estimated values by this model in estimating the reference evapotranspiration.

\section{Discussion}

In general, the performance of models in estimating $R s$ values was similar, although it was possible to recognise that $\mathrm{BC}, \mathrm{CH}, \mathrm{DC}$ and JS models had a better performance, when compared to AN, HA, HA-1 and HU models. One of the explanations for this variation of performance between the models can be attributed to the manner, in which each coefficient is inserted into the equation. The solar radiation is the primary source of energy for the change of weather elements and various processes occurring on the surface and in the atmosphere (Pereira et al., 2007; Wu, et al., 2007). Therefore, the greater the amount of energy used for the change of a particular element, the greater the representation on the total amount available and vice versa. As reported by Bristow and Campbell (1984), the balance of daily radiation can be expressed by the Bowen ratio (sensible heat/latent heat) and provides valuable microclimate information. According to these authors, in the $\mathrm{BC}$ model the $b$ and $c$ coefficients indicate the energy partition and the coefficient $a$ is related to atmospheric transmissivity (altitude and air pollution, mainly). This feature is important for locations that dominate two distinct annual seasons (one predominantly dry 
Table 1. Meteorological station sites, period of evaluation, percentage of data omission, annual mean temperature air range ( $\triangle T a)$, mean, minimum, maximum daily solar radiation incident on surface (Rs, Rsmin, Rsmax).

\begin{tabular}{|c|c|c|c|c|c|c|c|c|c|}
\hline Location & Latitude & Longitude & $\begin{array}{l}\text { Altitude } \\
(\mathrm{m})\end{array}$ & Period & $\begin{array}{l}\text { Omission } \\
(\%)\end{array}$ & $\begin{array}{l}\Delta T a \\
\left({ }^{\circ} \mathrm{C}\right)\end{array}$ & Rsmin & Rsmax & $R s m$ \\
\hline Araxa & $-19.60^{\circ}$ & $-46.93^{\circ}$ & 1.020 & $2009-2014$ & 4.93 & 10.53 & 2.28 & 35.74 & 19.74 \\
\hline $\begin{array}{l}\text { Conc. das } \\
\text { Alagoas }\end{array}$ & $-19.99^{\circ}$ & $-48.15^{\circ}$ & 568 & 2009-2014 & 5.16 & 13.38 & 1.85 & 33.08 & 18.33 \\
\hline Ituiutaba & $-18.95^{\circ}$ & $-49.52^{\circ}$ & 560 & 2009-2014 & 1.41 & 13.48 & 2.52 & 30.20 & 18.90 \\
\hline Patrocinio & $-19.00^{\circ}$ & $-46.99^{\circ}$ & 963 & $2009-2014$ & 1.00 & 13.46 & 2.56 & 31.76 & 18.98 \\
\hline Sacramento & $-19.88^{\circ}$ & $-47.43^{\circ}$ & 912 & 2009-2014 & 1.87 & 11.53 & 1.78 & 30.79 & 18.64 \\
\hline Uberlandia & $-18.92^{\circ}$ & $-48.25^{\circ}$ & 869 & 2009-2014 & 3.88 & 10.30 & 1.90 & 35.76 & 18.86 \\
\hline
\end{tabular}

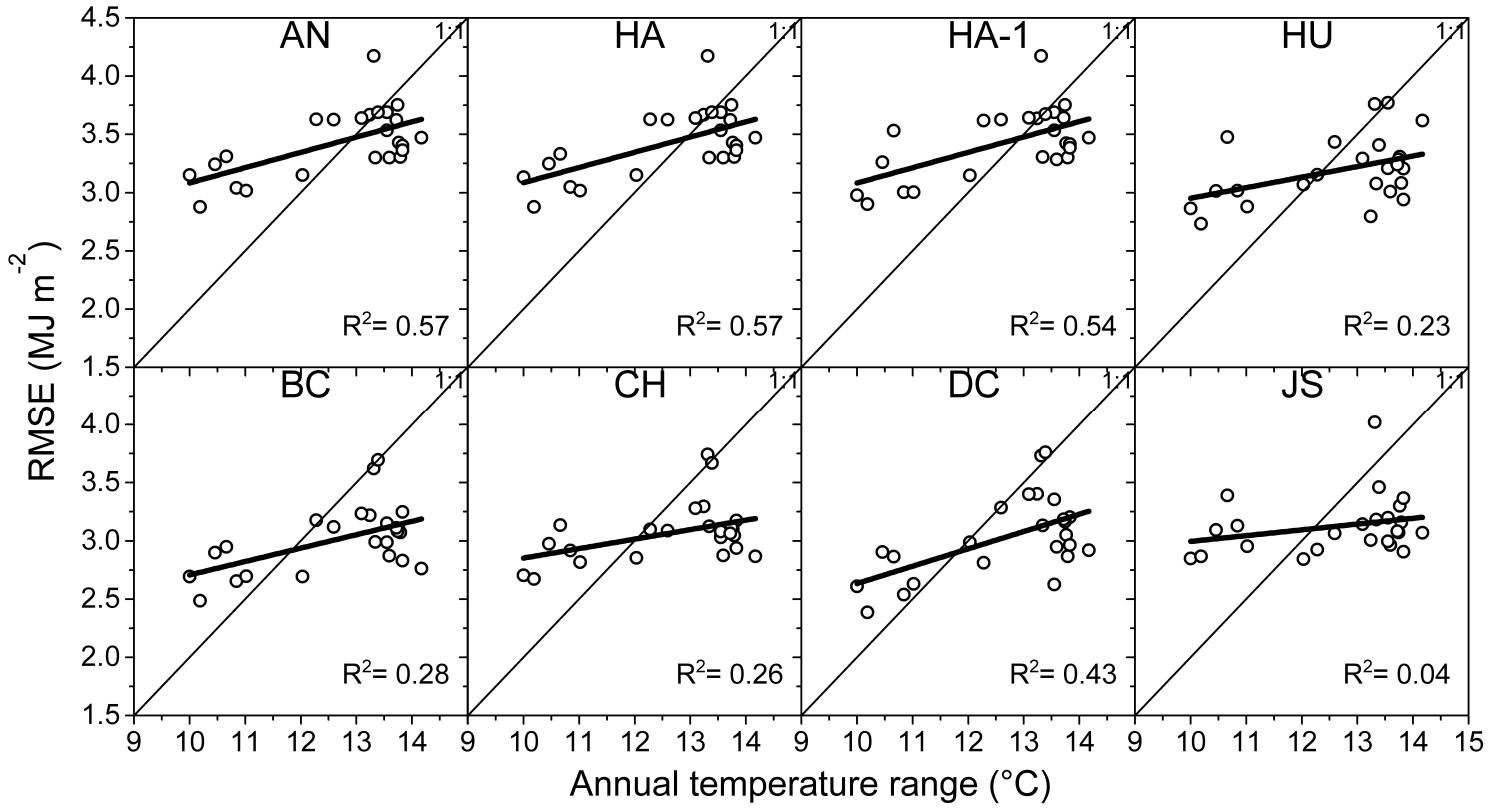

Fig 1. Analysis of regression between annual temperature range $(\triangle T a)$ and root mean square error $(R M S E)$ of $R s$ estimation models calculated on six sites for each model: AN-Annandale, BC-Bristow and Campbell, $\mathrm{CH}-\mathrm{Chen}$, DC-Donatelli and Campbell, HAHargreaves, HA-1-modified Hargreaves, HU-Hunt, and JS-De Jong and Stewart.

and the other rainy), such as the locations in this study. Therefore, for the rainy season, a larger portion of the daily radiation balance is spent on latent heat rather than with sensible heat and the coefficients $b$ and $c$ of the $\mathrm{BC}$ model control this partition during the year. Bellocchi et al. (2003) found better answers to the simulation of crop biomass for models that include seasonal effects on $R s$ estimates, when evaluating three $R s$ estimation models in different locations. On the other hand, the AN, HA, HA-1 and HU models do not have coefficients that indicate such partition of energy. The coefficients in these models are more related to atmospheric transmissivity, leaving important information as to microclimate aside.

Other consideration is about how the air temperature range $(\Delta T)$ is calculated. These models do not use a 2-day averaging minimum air temperature to obtain $\Delta T$, which could help to reduce the effect of large scale clouds moving through the study area in a day, reducing $R s$ but not $\Delta T$. Therefore, this may explain the strong trend of these models in overestimating $R s$ in rainy summer. When the average $R s$ values were close to $5 \mathrm{MJ} \mathrm{m} \mathrm{d}^{-1}$, the estimated values for these models were more than double. However, this is not a problem verified in many studies. Liu et al. (2009b), in China, observed only a moderate effect of $\Delta T$ scheme and for most locations, $\Delta T$ used by these models was even more precise.
When the Rs estimated data were used in SOYSIM software, the $\mathrm{BC}, \mathrm{CH}, \mathrm{DC}$ and JS models showed greater efficiency, having estimates close to those obtained with $R s$ measured at the location. With the $R s$ estimated by these models, the potential yield did not exceed by $7 \%$. On the other hand, the AN, HA, HA-1 and HU models overestimated the yield up to $34 \%$. Probably, one reason was that as the yield estimates were carried out for a relatively short period of the year (105 days on average) and under rainy summer, the overestimated $R s$ values were used by An, HA, HA-1 models. As biomass accumulation is proportional to the amount of light in the photosynthetically active radiation (PAR) domain that the plant intercepts over a period of time (Monteith, 1977), another reason could be the major impact of these values in potential soybean yield simulated by SOYSIM software.

It is noteworthy that the statistical indices are widely used to evaluate performances of $R s$ estimation models. However, depending on the application of the estimated data, small differences in these performances can reduce efficiency in dependent applications, as crop yield simulation. This work showed that when the estimated $R s$ data were used to simulate the potential yield, the performances of some models decreased considerably.

Another observation is about the importance of model calibration. Wang et al. (2015) found no significant differences between the estimations obtained with 
Table 2. Summary of the studied models.

\begin{tabular}{llll}
\hline Model & Equation & Coefficient & Source \\
\hline AN & $R s=a\left(1+2,710^{-5} A l t\right) \sqrt{\Delta T_{1}} R a$ & $a$ & Annandale et al. (2002) \\
BC & $R s=a\left(1-\exp \left(-b \Delta T_{2}^{c}\right)\right) R a$ & $a, b, c$ & Bristow and Campbell (1984) \\
CH & $R s=\left(a \ln \Delta T_{1}+b\right) R a$ & $a, b$, & Chen et al. (2004) \\
JS & $R s=a \Delta T_{1}^{b}\left(1+c P+d P^{2}\right) R a$ & $a, b, c, d$ & De Jong and Stewart (1993) \\
DC & $R s=a\left(1-\exp \left(-b \frac{\Delta T_{2}^{c}}{\Delta T m}\right)\right) R a$ & $a, b, c$ & \\
HA & $R s=a \sqrt{\Delta T_{1}} R a$ & $a$ & Donatelli and Campbell (1998) \\
HA-1 & $R s=a \sqrt{\Delta T_{1}} R a+b$ & $a, b$ & Hargreaves (1981) \\
HU & $R s=a \sqrt{\Delta T_{1}} R a+b T m a ́ x+c P+d P^{2}+e$ & $a, b, c, d, e$ & Hunt et al. (1998) \\
\hline
\end{tabular}

Where: $R s$, daily solar radiation incident on the sur number of day of the year (Allen et al., 1998); $A l t$, altitude (meters); $\Delta T_{1}$, difference between the maximum and minimum air temperature of the day $\left({ }^{\circ} \mathrm{C}\right) ; \Delta T_{2}$, difference between the maximum and the average of the minimum air temperature of the two consecutive days $\left({ }^{\circ} \mathrm{C}\right) ; \Delta T m$, monthly mean of the $\Delta T_{2}$, and; $P$, daily rainfall (mm).

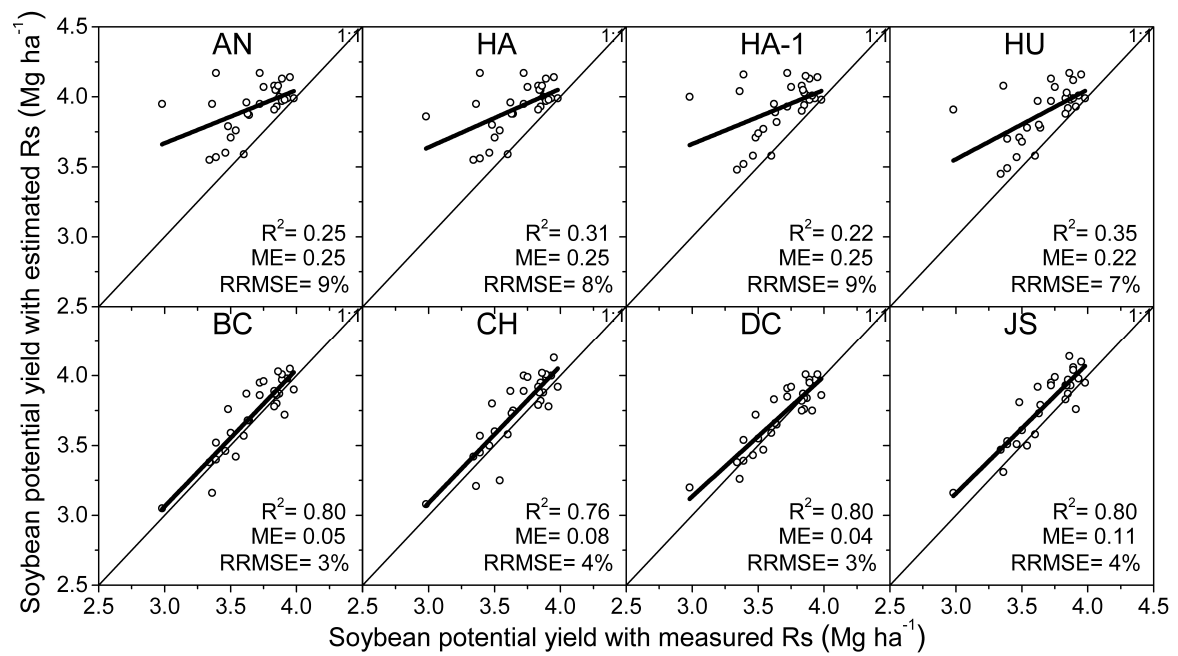

Fig 2. Analysis of regression between yield simulations with $R s$ measured and estimated by the models to Triangulo Mineiro region: AN-Annandale, BC-Bristow and Campbell, $\mathrm{CH}-\mathrm{Chen}, \mathrm{DC}-$ Donatelli and Campbell, HA-Hargreaves, HA-1-modified Hargreaves, HU-Hunt, and JS-De Jong and Stewart.

calibrated and uncalibrated models, when evaluating $R s$ models based on insolation. However, they noted that the $R s$ data estimated without local calibration used in the crop simulation models significantly affected the results.

\section{Materials and Methods}

\section{Data}

Meteorological data were obtained from six weather stations localized in the Triangulo Mineiro region and listed in Table 1. The stations are part of the National Meteorology Institute (INMET) network. In these stations, for Rs daily measurements, a CM6B pyranometer (Kipp and Zonen, Delft, Netherlands, 5\% of accuracy) was used. The air temperature was measured with QMH102 (Vaisala, Finland, $0.1^{\circ} \mathrm{C}$ of accuracy) and daily rainfall was measured with QMR102 tipping-bucket rain gauge (Vaisala, Finland, 0.2 $\mathrm{mm}$ of accuracy). All data were available at the web site http://www.inmet.gov.br
The data recorded at hourly intervals were processed to get daily values of maximum (Tmax) and minimum air temperature (Tmin); solar radiation $(R s)$, and rainfall $(P)$. Data were checked for outliers by elimination criteria proposed by Liu et al. (2009b): (a) missing measurements for any Tmax, Tmin or $R s$; (b) Tmax $\leq T \operatorname{Tmin}$ and (c) $R s / R a \geq 1$. Omission of data (Table 1) was calculated dividing missing data with total available. Daily extraterrestrial solar radiation was calculated according to the latitude and the number day of the year (Allen et al., 1998)

\section{Solar radiation models}

Table 2 shows the models used to estimate Rs. Hargreaves (1981) was the first to propose a model for estimating $R s$ from the difference between maximum and minimum air temperatures. Since then, Hargreaves's model has been widely used due to its simplicity. The original Hargreaves model had only one coefficient, but some authors have cited it as having two (Hunt et al., 1998; Chen et al., 2004). Over time, modifications have been proposed to the model. 
Table 3. Models coefficients calibrated in the studied sites.

\begin{tabular}{|c|c|c|c|c|c|c|c|c|c|c|c|}
\hline \multirow[b]{3}{*}{ Stations } & \multicolumn{11}{|c|}{ Models* } \\
\hline & \multirow{2}{*}{$\begin{array}{c}\mathrm{AN} \\
a\end{array}$} & \multicolumn{3}{|c|}{$\mathrm{BC}$} & \multicolumn{2}{|c|}{$\mathrm{CH}$} & \multicolumn{5}{|c|}{ JS } \\
\hline & & $a$ & $b$ & $c$ & $a$ & $b$ & $a$ & $b$ & \multicolumn{2}{|c|}{$c$} & $d$ \\
\hline Araxa & 0.183 & 0.862 & 0.017 & 1.861 & 0.513 & -0.575 & 0.076 & 0.903 & \multicolumn{2}{|c|}{$-5.90 \mathrm{E}-3$} & $6.02 \mathrm{E}-5$ \\
\hline Conc. das alagoas & 0.150 & 0.695 & 0.019 & 1.767 & 0.373 & -0.387 & 0.079 & 0.763 & \multicolumn{2}{|c|}{$-9.66 \mathrm{E}-4$} & $-6.60 \mathrm{E}-7$ \\
\hline Ituiutaba & 0.152 & 0.677 & 0.012 & 1.997 & 0.391 & -0.436 & 0.085 & 0.733 & \multicolumn{2}{|c|}{$-8.70 \mathrm{E}-5$} & $-2.20 \mathrm{E}-5$ \\
\hline Patrocinio & 0.153 & 0.873 & 0.039 & 1.304 & 0.383 & -0.401 & 0.076 & 0.787 & \multicolumn{2}{|c|}{$3.95 \mathrm{E}-3$} & $-1.11 \mathrm{E}-4$ \\
\hline Sacramento & 0.155 & 0.796 & 0.019 & 1.711 & 0.436 & -0.504 & 0.059 & 0.923 & \multicolumn{2}{|c|}{$-3.93 \mathrm{E}-3$} & $6.31 \mathrm{E}-5$ \\
\hline Mean & 0.160 & 0.772 & 0.020 & 1.769 & 0.425 & -0.466 & 0.075 & 0.832 & \multicolumn{2}{|c|}{---} & --- \\
\hline Models & \multicolumn{3}{|c|}{$\mathrm{DC}$} & HA & \multicolumn{2}{|c|}{ HA-1 } & \multicolumn{5}{|c|}{$\mathrm{HU}$} \\
\hline Stations & $a$ & $b$ & $c$ & $a$ & $a$ & $b$ & $a$ & $b$ & $c$ & $d$ & $e$ \\
\hline Araxa & 0.758 & 0.064 & 2.413 & 0.188 & 0.179 & 0.983 & 0.131 & 0.543 & -0.236 & 0.003 & -7.899 \\
\hline Conc. das alagoas & 0.654 & 0.115 & 2.067 & 0.153 & 0.175 & -2.639 & 0.154 & 0.168 & -0.117 & 0.002 & -5.017 \\
\hline Ituiutaba & 0.687 & 0.084 & 2.182 & 0.153 & 0.201 & -5.914 & 0.172 & 0.286 & -0.086 & 0.001 & -10.982 \\
\hline Patrocínio & 0.688 & 0.152 & 1.961 & 0.157 & 0.162 & -0.593 & 0.141 & 0.211 & -0.082 & 0.001 & -3.730 \\
\hline Uberlandia & 0.649 & 0.030 & 2.812 & 0.169 & 0.154 & 1.611 & 0.120 & 0.468 & -0.265 & 0.004 & -7.415 \\
\hline Mean & 0.686 & 0.089 & 2.251 & 0.163 & 0.172 & -1.089 & 0.142 & 0.327 & -0.168 & 0.003 & -6.622 \\
\hline
\end{tabular}

* Models: AN-Annandale, BC-Bristow and Campbell, CH-Chen, DC-Donatelli and Campbell, HA-Hargreaves, HA-1-modified Hargreaves, HU-Hunt, and JS-De Jong and Stewart.

Table 4. Performance of the solar radiation estimation models in the six sites of Triangulo Mineiro region: Coefficient of determination $\left(R^{2}\right)$, Mean bias error $(M E)$, root mean square error (RMSE) and relative root mean square error (RRMSE).

\begin{tabular}{|c|c|c|c|c|c|c|c|c|}
\hline \multirow{2}{*}{ Sites $^{\mathrm{a}}$} & \multicolumn{8}{|c|}{ Models $^{\mathrm{b}}$} \\
\hline & AN & HA & HA-1 & HU & $\mathrm{BC}$ & $\mathrm{CH}$ & $\mathrm{DC}$ & JS \\
\hline & \multicolumn{8}{|l|}{$R^{2}$} \\
\hline 1 & 0.54 & 0.54 & 0.54 & 0.65 & 0.67 & 0.66 & 0.66 & 0.68 \\
\hline 2 & 0.64 & 0.64 & 0.64 & 0.68 & 0.72 & 0.70 & 0.74 & 0.67 \\
\hline 3 & 0.63 & 0.63 & 0.63 & 0.66 & 0.71 & 0.68 & 0.74 & 0.63 \\
\hline 4 & 0.58 & 0.58 & 0.58 & 0.63 & 0.68 & 0.67 & 0.67 & 0.65 \\
\hline 5 & 0.55 & 0.55 & 0.55 & 0.57 & 0.67 & 0.68 & 0.66 & 0.66 \\
\hline \multirow[t]{2}{*}{6} & 0.48 & 0.48 & 0.48 & 0.60 & 0.59 & 0.59 & 0.59 & 0.62 \\
\hline & \multicolumn{8}{|c|}{$M E\left(M J m^{-2} d^{-1}\right)$} \\
\hline 1 & +0.96 & +0.96 & +0.96 & +1.15 & +1.34 & +1.12 & +0.76 & +1.43 \\
\hline 2 & +0.28 & +0.28 & +0.34 & +0.27 & +0.62 & +0.64 & -0.02 & +0.85 \\
\hline 3 & +0.05 & -0.16 & -0.06 & -0.04 & -0.05 & +0.07 & -0.40 & +0.19 \\
\hline 4 & +0.28 & +0.28 & +0.29 & +0.33 & +0.79 & +0.46 & -0.13 & +0.71 \\
\hline 5 & -0.63 & -0.63 & -0.63 & -0.34 & -0.12 & -0.28 & -0.80 & +0.10 \\
\hline \multirow[t]{2}{*}{6} & -0.66 & -0.66 & -0.66 & -0.49 & -0.20 & -0.13 & -0.76 & -0.08 \\
\hline & \multicolumn{8}{|c|}{$R M S E\left(M J m^{-2} d^{-1}\right)$} \\
\hline 1 & 3.94 & 3.94 & 3.93 & 3.55 & 3.76 & 3.78 & 3.60 & 3.68 \\
\hline 2 & 3.29 & 3.29 & 3.26 & 3.07 & 2.92 & 3.02 & 2.76 & 3.23 \\
\hline 3 & 3.05 & 3.06 & 3.09 & 2.98 & 2.67 & 2.84 & 2.60 & 3.02 \\
\hline 4 & 3.33 & 3.33 & 3.33 & 3.12 & 3.03 & 3.04 & 3.03 & 3.18 \\
\hline 5 & 3.68 & 3.68 & 3.68 & 3.50 & 3.08 & 3.09 & 3.26 & 3.13 \\
\hline \multirow[t]{2}{*}{6} & 3.61 & 3.61 & 3.61 & 3.15 & 3.25 & 3.27 & 3.37 & 3.14 \\
\hline & \multicolumn{8}{|c|}{ RRMSE (\%) } \\
\hline 1 & 20.04 & 20.04 & 19.99 & 18.04 & 19.12 & 19.21 & 18.34 & 18.72 \\
\hline 2 & 17.80 & 17.80 & 17.64 & 16.62 & 15.78 & 16.34 & 14.93 & 17.45 \\
\hline 3 & 15.94 & 15.99 & 16.18 & 15.57 & 13.98 & 14.87 & 13.62 & 15.87 \\
\hline 4 & 17.46 & 17.46 & 17.45 & 16.35 & 15.91 & 15.94 & 15.86 & 16.64 \\
\hline 5 & 19.47 & 19.47 & 19.47 & 18.50 & 16.29 & 16.36 & 17.27 & 16.58 \\
\hline 6 & 18.93 & 18.93 & 18.92 & 16.53 & 17.03 & 17.16 & 17.68 & 16.45 \\
\hline
\end{tabular}


Chen et al. (2004) replaced the exponential function by a logarithmic function. De Jong and Stewart (1993) and Hunt et al. (1998) introduced more coefficients for corrections of rainfall effect. Annandale et al. (2002) introduced a correction factor for altitude. Another air temperature empirical model with more physics was involved in the relationship proposed by Bristow and Campbell (1984). The model has three coefficients, where $a$ represents the maximum transmissivity expected for one clear day, which will vary with altitude air pollution and, $b$ and $c$, control the rate as to how soon the maximum $R s$ is achieved as $\Delta T$ increases. To reduce the effect of large-scale hot or cold air masses, which may move through the area, the range of air temperature was calculated as the difference between maximum and average minimum air temperature of the two consecutive days. Donatelli and Campbell (1998) proposed a correction to reduce the seasonal effect on $R s$, dividing the temperature range by the month average.

\section{Calibration}

The dataset (2009-2014) was separated into two sub-datasets, one for calibration (2009) and the other for evaluating the performance (2010-2014). Nonlinear least square method (RMSE) was used to calibrate model coefficients by the solver tool of EXCEL software.

\section{Potential Soybean yield with Rs estimated values}

After calibration, $R s$ estimated values for each model were used to simulate the potential soybean yield in five consecutive seasons using SoySim (version 2009.1.0). The software simulated the potential soybean yield through $R s$, maximum and minimum air temperature, photoperiod and sowing densities (Setiyono et al., 2010). Default crop parameters for soybean were used. The emergence date at each location was set $15^{\text {th }}$ of November using a soybean cultivar of semi-determinate growth, and 7.0 maturity group.

\section{Statistical analysis}

To perform an evaluation of the models for estimating $R s$ statistical indexes such as: (a) root mean square error (RMSE), (b) relative root mean square error (RRMSE), (c) coefficient of determination $\left(R^{2}\right)$, and (d) mean bias error $(M E)$ or $B I A S$, by equations $1,2,3$ and 4 were used. The impact of $R s$ estimated values on potential yield of soybean was also analyzed by these statistical indexes.

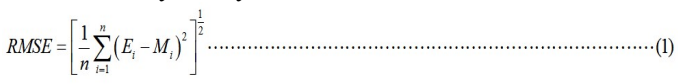

$$
\begin{aligned}
& R R M S E=\left[\frac{1}{n} \sum_{i=1}^{n} \quad\left(E_{i}-M_{i}\right)^{2}\right]^{\frac{1}{2}} \frac{100}{\bar{M}} \\
& R^{2}=\left[\begin{array}{ll}
\sum_{i=1}^{n} & \left(E_{i}-M_{i}\right)^{2} \\
\hline \sum_{i=1}^{n} & \left(E_{i}-\bar{M}\right)^{2}
\end{array}\right] \\
& M E=\frac{1}{n} \sum_{i=1}^{n}\left(E_{i}-M_{i}\right)
\end{aligned}
$$

Where,

$M_{i}$ - potential soybean yield with $R s$ observed values, $\mathrm{Mg}$ ha ${ }^{1} ; E_{i}$ - potential soybean yield with $R s$ estimated values, $\mathrm{Mg}$ $\mathrm{ha}^{-1} ; n$-total data; $\bar{M}$-mean potential soybean yield with $R s$ measured values, $\mathrm{Mg}_{\mathrm{ga}}{ }^{-1}$.

\section{Conclusion}

Daily solar radiation estimation data based on air temperature and/or rainfall were used in Soybean crop yield simulation. After calibration, although the $R s$ estimated by the eight models presented similar performance, when these data were used in the simulation of the potential soybean yield, the performances diverged considerably. Thus, all the models showed a general tendency to overestimate the potential soybean yield, but in AN, HA, HA-1 and HU models this tendency was higher than other models. In this way, only BC, $\mathrm{CH}, \mathrm{DC}$ and JS models showed satisfactory performance in yield simulation with $R^{2}$ and $R R M S E$ varying from 0.76 to 0.80 and 3 to $4 \%$, respectively. Therefore, this study showed that, before choosing the model to estimate $R s$, it is important to define the purpose of the results obtained considering the range of data available for their calibration.

\section{Acknowledgements}

The authors thank INMET (National Institute of Meteorology) by availability of data used in this study.

\section{References}

Abraha MG, Savage MJ (2008) Comparison of estimates of daily solar radiation from air temperature range for application in crop simulations. Agr For Meteorol. 148(3): 401-416.

Allen RG, Pereira LS, Raes D, Smith M (1998) Crop evapotranspiration: guidelines for computing crop water requirements. The FAO Irrigation and Drainage Paper 56. Rome, Italy.

Allen RG (1997) Self-calibrating method for estimating solar radiation from air temperature. J Hydrol Eng. 2: 56-67.

Almorox J, Bocco M, Willington E (2013) Estimation of daily global solar radiation from measured temperatures at Cañada de Luque, Córdoba, Argentina. Renew Energ. 60: 382-387.

Almorox J (2011) Estimating global solar radiation from common meteorological data in Aranjuez, Spain. Turk J Phys. 35: 53-64.

Annandale JG, Jovanic NZ, Benade N, Allen RG (2002) Software for missing data error analysis of PenmanMonteith reference evapotranspiration. Irrigation Sci. 21: 57-67.

Bandyopadhyay A, Bhadra A, Raghuwanshi NS, Singh R (2008) Estimation of monthly solar radiation from measured air temperature extremes. Agr Forest Meteorol. 148(11): 1707-1718.

Bellocchi G, Donatelli M, Fila G (2003) Evaluation of estimated radiation data for calculating evapotranspiration and crop biomass. Ital J Agron. 7: 95-102.

Borges VP, Oliveira AS, Coelho Filho MA, Silva TSM, Pamponet BM (2010) Evaluating models for estimation of incoming solar radiation in Cruz das Almas, Bahia, Brazil. Rev Bras Eng Agríc Ambient. 14(1): 74-80.

Bristow KL, Campbell GS (1984) On the relationship between incoming solar radiation and daily maximum and minimum temperature. Agr Forest Meteorol. 31(2): 159-166.

Carvalho DF, Silva DG, Souza AP, Gomes DP, Rocha HS (2011) Coefficients of the Angström-Prescott equation and its influence on evapotranspiration in Seropedica, Rio de Janeiro State, Brazil. Rev Bras Eng Agríc Ambient. 15(8): 838-844. 
Chen RS, Ersi K, Yang JP, Lu SH, Zhao WZ (2004) Validation of five global radiation models with measured daily data in China. Energ Convers Manage. 45: 17591769.

Conceição MAF (2010) Reference evapotranspiration based on solar radiation estimated by the Bristow-Campbell model. Agr Eng. 30(4): 619-626.

De Jong R, Stewart DW (1993) Estimating global solar radiation from common meteorological observations in western Canada. Can J Plant Sci. 73: 509-518.

Donatelli M, Campbell GS (1998) A simple model to estimate global solar radiation. The 5th European Society of Agronomy Congress. Nitra, Slovak Republic.

Dos Santos CM, De Souza JL, Ferreira Junior RA, Tiba C, Melo RO, Lyra GB, Teodoro I, Lyra GB, Lemes MAM (2014) On modeling global solar irradiation using air temperature for Alagoas State, Northeastern, Brazil. Energy. 71: 388-398.

El Nesr MN, Alazba AA, Amin MT (2011) Modified Hargreaves' method as an alternative to the PenmanMonteith method in Kingdom of Saudi Arabia. Aust J Basic Appl Sci. 5: 1058-1069.

Goodin DG, Hutchinson JMS, Vanderlip RL, Knapp MC (1999) Estimating solar irradiance for crop modeling using daily air temperature data. Agron J. 91: 845-851.

Hargreaves GH (1981) Responding to tropical climates, the food and climate review. The Food and Climate Forum, Aspen Institute for Humanistic Studies. Boulder, USA

Hossain S, Homma K, Shiraiwa T (2014) Decadal and monthly change of an empirical coefficient in the relation between solar radiation and the daily range of temperature in Japan: implication for the estimation of solar radiation based on temperature. Plant Prod Sci. 17: 333-341.

Hunt, L.A., Kucharb, L., Swanton, C.J., (1998). Estimation of solar radiation for use in crop modeling. Agr Forest Meteorol. 91: 293-300.

Liu X, Mei X, Li Y, Wang Q, Zhang Y, Porter JR (2009a) Variation in reference crop evapotranspiration caused by the Angström-Prescott coefficient: locally calibrated versus the FAO recommended. Agr Water Manage. 96: 11371145.

Liu X, Mei X, Li Y, Wang Q, Jensen RJ, Zhang Y, Porter JR (2009b) Evaluation of temperature-based global solar radiation models in China. Agr Forest Meteorol. 149(9): 1433-1446.
Mavromatis T (2008) Estimation of solar radiation and its application to crop simulation models in Greece. Clim Res. 36: 219-230.

Meza F, Varas E (2000) Estimation of mean monthly solar global radiation as a function of temperature. Agr Forest Meteorol. 100(2-3): 231-241.

Monteith JL (1977) Climate and the efficiency of crop production in Britain. Philos T Roy Soc B. 28: 277-294.

Pereira RA, Angelocci LR, Sentelhas PC (2007) Meteorologia agrícola. Departamento de Ciências Exatas, Esalq-USP, Piracicaba, 192

Phakamas N, Jintrawet A, Patanothai A, Sringam P, Hoogenboom G (2013) Estimation of solar radiation based on air temperature and application with the DSSAT v4.5 peanut and rice simulation models in Thailand. Agr Forest Meteorol. 180(10): 182-193.

Rivington M, Matthews KB, Bellocchi G, Buchan K (2006) Evaluating uncertainty introduced to process-based simulation model estimates by alternative sources of meteorological data. Agr Syst. 88: 451-471.

Setiyono TD, Cassman KG, Specht JE, Dobermann A, Weiss A, Yang H, Conley SP, Robinson AP, Pedersen P, De Bruin JL (2010) Simulation of soybean growth and yield in nearoptimal growth conditions. Field Crop Res. 119: 161-174.

Silva CR, Silva VJ, Alves Jr J, Carvalho HP (2012) Estimation of solar radiation by air temperature models for three regions of Minas Gerais. Rev Bras Eng Agríc Ambient. 16: 281-288.

Trnka M, Eitzinger J, Kapler P, Dubrovský M, Semerádová D, Zalud Z, Formayer H (2007) Effect of estimated daily global solar radiation data on the results of crop growth models. Sensors. 7: 2330-2362.

Wang J, Wang E, Yin H, Feng L, Zhao Y (2015). Differences between observed and calculated solar radiations and their impact on simulated crop yields. Field Crop Res. 176: 1-10.

Weiss A, Hays CJ (2004) Simulation of daily solar irradiance. Agr Forest Meteorol. 123(3-4): 187-199.

Wu G, Liu Y, Wang T (2007) Methods and strategy for modeling daily global solar radiation with measured meteorological data - A case study in Nanchang station, China. Energ Convers Manage. 48: 2447-2452. 